DOI: http://dx.doi.org/10.18203/2320-1770.ijrcog20201837

\title{
Twin reversed arterial perfusion sequence: the heartless twin
}

\author{
Ashwin Rao*, Rashmi Rao \\ Department of Obstetrics and Gynecology, Salem Polyclinic, Salem, Tamil Nadu, India \\ Received: 05 March 2020 \\ Accepted: 01 April 2020 \\ *Correspondence: \\ Dr. Ashwin Rao, \\ E-mail: ashwinrao2404@gmail.com \\ Copyright: (c) the author(s), publisher and licensee Medip Academy. This is an open-access article distributed under \\ the terms of the Creative Commons Attribution Non-Commercial License, which permits unrestricted non-commercial \\ use, distribution, and reproduction in any medium, provided the original work is properly cited.
}

\begin{abstract}
To report a case of twin reversal arterial perfusion sequence and its management by means of laser coagulation of the vascular malformation in the placenta. Twin reversed arterial perfusion sequence is a rare form of twin to twin transfusion syndrome occurring primarily in Monochorionic monoamniotic twins. The prevalence is about 1 in 35,000 pregnancies. The significance of this condition is that there is a normal foetus and an acardiac foetus. The blood is shunted from the normal twin to the acardiac twin through vascular malformations in the placenta. The normal twin faces a high risk of both morbidity and mortality due to cardiac failure. A case of twin reversal arterial perfusion sequence diagnosed at 22 weeks following a target scan underwent laser photocoagulation and gave birth vaginally at 30 weeks without any complications. Early detection of this condition can lead to timely intervention and thereby improve the outcome. In Twin reversal arterial perfusion sequence, the normal or the pump twin has a high chance of mortality due to cardiac failure. As the size of the acardiac twin increases, there is a higher chance of mortality of the pump twin. There is a need for regular follow up with ultrasonography and foetal echocardiography along with early therapeutic interventions to ensure the survival of the normal twin. In our case, despite the large size of the acardiac twin, we had a successful pregnancy outcome for the normal twin due to timely intervention.
\end{abstract}

Keywords: Acardiac twin, Complication of twins, Laser photocoagulation, Monochorionic monoamniotic twin, Perfused twin, Radiofrequency ablation, Twin to twin transfusion, Twin reversed arterial perfusion sequence

\section{INTRODUCTION}

Twin reversed arterial perfusion sequence (TRAP) is a form of acardiac twinning seen in twin to twin transfusion occurring among monozygotic monochorionic twins and it is a rare anomaly. The general incidence is that it occurs in $1 \%$ of the monozygotic twins and it overall occurs in 1 in 35,000 pregnancies. ${ }^{1}$ The pathophysiology behind TRAP sequence is that there may be arterio-arterial or venovenous anastomosis in the placenta. There is a donor twin and a recipient twin and blood are pumped from the normal to the acardiac twin. ${ }^{2}$ The first case was described by Benedetti in 1533 and very few cases have been described since then. ${ }^{3}$

The pump twin has to maintain a high cardiac output due to abnormal circulation and hence develops cardiac failure and may also have IUGR. The anomalous twin may either appear to be a heterogeneous mass or an intrauterine foetal demise. Acardiac twinning is associated with high risk chromosomal abnormalities $(33 \%)$ and single umbilical artery $(66 \%)$. The development of the lower part of the abnormal twin is due to perfusion of tissues with deoxygenated blood from the lower branches of the aorta. A higher risk of polyhydramnios and preterm labour is observed when the weight ratio between the acardiac and pump twin exceeds $50 \%$. Reversal of umbilical artery blood flow in the abnormal twin on Doppler examination points to the diagnosis.

\section{CASE REPORT}

A 20-year-old primi childbearing woman at 22 weeks of gestation came for a routine second trimester anomaly 
scan. She had $3^{\text {rd }}$ degree consanguineous marriage and was married for 11 months. Ultrasound examination showed monochorionic monoamniotic twins with normal fetus (fetus A) of gestational age 21-22 weeks with polyhydramnios with no obvious anomalies and an amorphous heterogeneous mass (fetus B). The effective fetal weight of fetus A was $465 \pm 46.5$ grams (Figure 1).

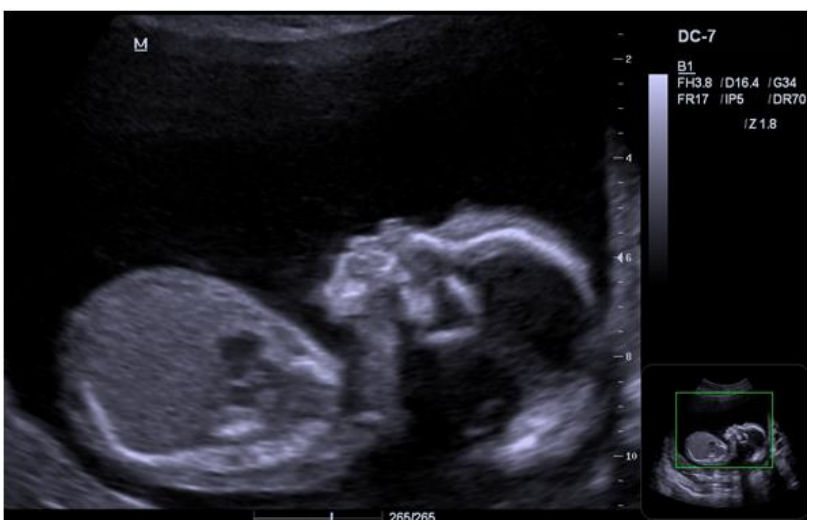

Figure 1: Fetus A - normal "pump" twin.

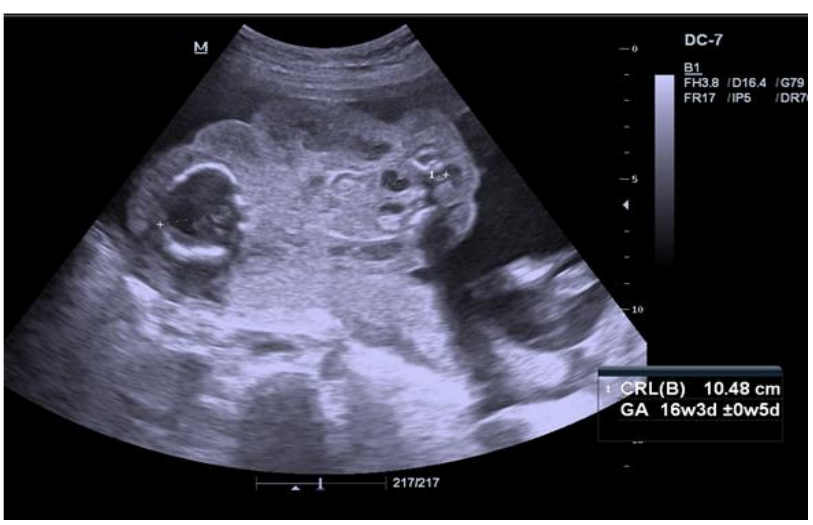

Figure 2: Fetus B - "perfused twin" - amorphous mass.

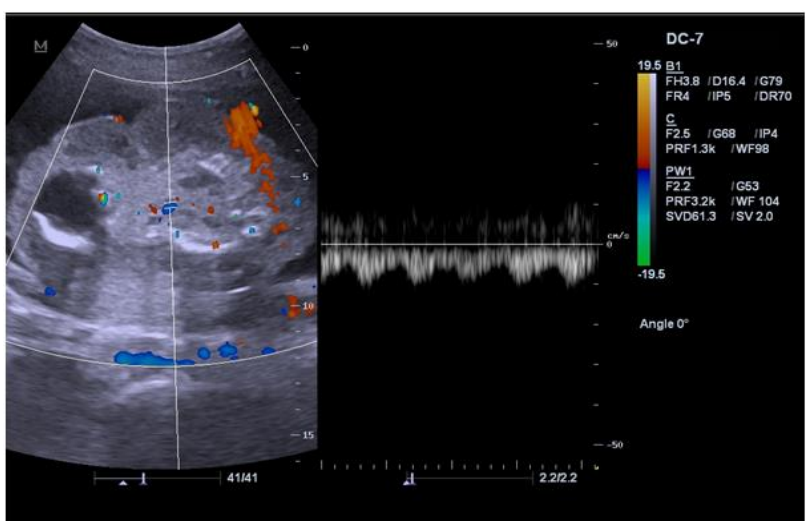

Figure 3: Pulse wave Doppler of the umbilical artery of the abnormal fetus $B$ showing reversal of flow in spectral waveform.

The fetal echo of fetus A showed Situs solitus and levocardia with cardiac chamber asymmetry. There was also associated mild tricuspid regurgitation. Fetal Doppler of fetus A showed normal flow in the middle cerebral artery and the umbilical artery but ductus venosus showed a high resistance flow. A large single placenta was seen in the posterior and left lateral part of the uterus. Fetus B had a partially fused head, thorax and lower limbs but no heart or upper limbs (Figure 2). The fetus B had a volume of $383.53 \mathrm{cc}$. A pulsed Doppler imaging of the fetus B showed reversal of blood flow. (Figure 3) Hence a diagnosis of TRAP sequence was made. The patient was advised to undergo laser coagulation of the vascular malformation. Post ultrasound guided laser coagulation, fetus A showed normal cardiac activity and blood ceased to flow to the TRAP fetus. Fetus A also showed normal Doppler study post procedure. The patient was followed up with serial ultrasound examinations. At 30 weeks of gestation, she had spontaneous onset of labour and gave birth vaginally to a normal male fetus weighing $1.28 \mathrm{kgs}$ and an amorphous mass.

\section{DISCUSSION}

In Craniopagus parasiticus or TRAP syndrome, there is blood flow from the normal twin (pump twin) to the abnormal twin ('perfused' twin) through abnormal vascular placental communications which may be arterial or venous. The blood flow is a reversed in the recipient twin wherein the oxygenated blood flows through abnormal anastomosis in the placenta to the umbilical artery, then flows cephalad and then out through the umbilical vein. ${ }^{2}$ Hence the spectral waveform of the reversal of flow can be visualized using a pulse wave Doppler of the umbilical artery of the 'perfused' twin.

Congenital anomalies may be seen in $9 \%$ of the pump twins. The overall perinatal mortality of pump twins is About $50-55 \%$ of the normal twins do not survive the perinatal period. ${ }^{4}$ The general cause of morbidity is premature delivery owing to polyhydramnios or secondary to congestive cardiac failure due to abnormal interfetal circulation and increased cardiac output. The high cardiac output causes increased perfusion of the kidneys leading to increased urine output and polyhydramnios. An ultrasound based prognostic indicator for survival chances of the normal foetus is by calculating the resistive index (RI). If the difference in the RI of the umbilical arteries between the pump twin and 'perfused' twin is greater than 0.20 , the prognosis is generally good. ${ }^{5}$

Due to the fact that the normal pump twin faces mortality or morbidity, various techniques have been devised to improve its outcome. In the perinatal period, treatment modalities include ligation or laser or bipolar coagulation of the umbilical cord using a fetoscope or radiofrequency ablation of the foetus. ${ }^{6}$ Risk factors requiring surgical intervention include:

- Polyhydramnios (maximum vertical pocket $\geq 8 \mathrm{~cm}$ ). 
- Large TRAP twin (the difference in estimated foetal 'perfused' twin weight and the donor twin is $50 \%$ or greater). The 'perfused' twin weight is obtained by: $\left(1.2 \times\right.$ longest length $\left.{ }^{2}\right)-(1.7 \times$ longest length $){ }^{7}$

- Cardiac failure observed in the pump twin, or Doppler ultrasound of the pump twin shows abnormal patterns of blood flow patterns (persistence of absent or reversal of umbilical artery diastolic flow, pulsatile flow is observed in the umbilical vein, reversal of flow in the ductus venosus and/or MCA PSV>1.5 times MoM).

- Monochorionic monoamniotic twins.

Prior to planning surgical treatment, congenital anomalies in pump twin, abnormal karyotype, ruptured membranes, chorioamnionitis have to be ruled out.

Diagnosis of TRAP sequence earlier in pregnancy by transvaginal ultrasonography with Doppler improves the prognosis as higher chances of pump twin demise in observed between 11-20 weeks. ${ }^{8}$ Although diagnosis was made early in gestation, due to the risks of miscarriage; intrauterine corrective measures were not taken before 15 weeks' gestation in order to wait till the obliteration of the celomic cavity. Before 16 weeks, radiofrequency ablation and intrafetal laser coagulation of the vascular malformation were found to be safe. Pagani et al also concluded that, laser coagulation prior to 16 weeks gestation was safer with fewer complications. ${ }^{9}$

TRAP sequence when treated using intrafetal radiofrequency ablation showed favorable results, there were chances of thermal injury which can lead to exsanguination of the pump during the procedure which may result in hemorrhagic manifestations in the fetus and death. ${ }^{10} \mathrm{~A}$ recent early intervention includes external beam of high-intensity focused ultrasound has been found to stop of blood flow within the acardiac twin, but further investigations are required to test the efficacy and safety. ${ }^{1,12}$ Early prophylactic intervention by 16 weeks is better as it may preclude technical difficulties of achieving arrest of flow in larger acardiac masses at later weeks.

Pregnancy termination is an option at early gestational ages whereas expectant management can be allowed in others. The survival rate of the pump twin is better with therapeutic invention which abruptly ceases blood flow to acardiac twin when compared to expectant management. ${ }^{13}$ Chaveeva $\mathrm{P}$ et al found that among 60\% of the cases diagnosed between 11-14 weeks, blood flow to the acardiac twin stopped spontaneously even before the intervention planned was executed at 16-18 weeks.

An inverse relationship between period of gestation at treatment and period of gestation at birth was observed when treated with laser coagulation at 12-27 weeks. Hence early intervention in TRAP sequence significantly decreased the mortality of the pump twin. ${ }^{14}$

\section{Clinical significance}

In twin reversal arterial perfusion sequence, the normal or the pump twin has a high chance of mortality due to cardiac failure. As the size of the acardiac twin increases, there is a higher chance of mortality of the pump twin. There is a need for regular follow up with ultrasonography and fetal echocardiography along with early therapeutic interventions to ensure the survival of the normal twin. In our case, despite the large size of the acardiac twin, we had a successful pregnancy outcome for the normal twin due to timely intervention.

\section{CONCLUSION}

When TRAP sequence is diagnosed early and appropriate mode of management is chosen at the correct gestational age following proper counseling of the patient, the results are favorable in multifetal gestations.

Funding: No funding sources

Conflict of interest: None declared

Ethical approval: Not required

\section{REFERENCES}

1. Barth RA, Crow HC. Ultrasound evaluation of multifetal gestations. In: Callen PW, editor. Callen ultrasonography in obstetrics and gynaecology. $4^{\text {th }}$ ed. Pennsylvania: WB Saunders; 2000:196-198.

2. Weber MA, Sebire NJ. Genetics and developmental pathology of twinning. Semin Fetal Neonatal Med. 2010;15(6):313-8.

3. Shashidhar B, Kumar BN, Sheela R, Kalyani R, Anithae N, Reddy PS. Twin reversed arterial perfusion (TRAP) sequence: (Acardius Amorphous) a case report and review of literature. Int J Biol Med Res. 2012;3:1453-5.

4. Levi CS, Lyons EA, Martel MJ. Sonography of multifetal pregnancy. In: Carol M, Rumack, editors. Diagnostic ultrasound. $3^{\text {rd }}$ ed. Vol. 2. Missouri: Elsivier Mosby; 2005:1207-1209.

5. Dashe JS, Fernandez CO, Twickler DM. Utility of Doppler velocimetry in predicting outcome in twin reversed-arterial perfusion sequence. Am J Obstet Gynecol. 2001;185(1):135-9.

6. Jelin E, Hirose S, Rand L, Curran P, Feldstein V, Guevara-Gallardo S, et al. Perinatal outcome of conservative management versus fetal intervention for twin reversed arterial perfusion sequence with a small acardiac twin. Fetal Diagn Ther. 2010;27(3):138-41.

7. Egan JF, Borgida AF. Ultrasound evaluation of multiple pregnancies. In: Callen PW, editor. Ultrasonography in obstetrics and gynecology. 5th ed. Pennsylvania: WB Saunders; 2008:286-288.

8. Schwärzler P, Ville Y, Moscosco G, Tennstedt C, Bollmann R, Chaoui R. Diagnosis of twin reversed arterial perfusion sequence in the first trimester by 
transvaginalcolor Doppler ultrasound. Ultrasound Obstet Gynecol. 1999;13(2):143-6.

9. Pagani G, D’Antonio F, Khalil A, Papageorghiou A, Bhide A, Thilaganathan B. Intrafetal laser treatment for twin reversed arterial perfusion sequence: cohort study and meta-analysis. Ultrasound Obstet Gynecol Off J IntSoc Ultrasound Obstet Gynecol. 2013;42(1):6-14.

10. Morel O, Malartic C, Barranger E. Radiofrequency ablation for twin-reversed arterial perfusion sequence: the unknown cord occlusion delay calls for long term neonatal follow-up of the surviving twins. Am J Obstet Gynecol. 2007;197(5):557-8.

11. Okai T, Ichizuka $\mathrm{K}$, Hasegawa J, Matsuoka R, Nakamura M, Shimodaira K, et al. First successful case of non-invasive in-utero treatment of twin reversed arterial perfusion sequence by highintensity focused ultrasound. Ultrasound Obstet Gynecol Off J Int Soc Ultrasound Obstet Gynecol. 2013;42(1):112-4.

12. Ichizuka K, Hasegawa J, Nakamura M, Matsuoka R, Sekizawa A, Okai T, et al. High-intensity focused ultrasound treatment for twin reversed arterial perfusion sequence. Ultrasound Obstet Gynecol. 2012;40(4):476-8.

13. Moore TR, Gale S, Benirschke K. Perinatal outcome of forty-nine pregnancies complicated by acardiac twinning. Am J Obstet Gynecol. 1990;163(3):90712.

14. Chaveeva P, Poon LC, Sotiriadis A, Kosinski P, Nicolaides KH. Optimal method and timing of intrauterine intervention in twin reversed arterial perfusion sequence: case study and meta-analysis. Fetal Diagn Ther. 2014;35(4):267-79.

Cite this article as: Rao A, Rao R. Twin reversed arterial perfusion sequence: the heartless twin. Int $\mathbf{J}$ Reprod Contracept Obstet Gynecol 2020;9:2201-4. 